UK/Japan projects in life sciences to target priority areas

\title{
Japan's universities 'need to strengthen links to industry'
}

London. Britain's Office of Science and Technology (OST) has been asked by the government to identify high priority areas for collaborative projects in the biological sciences that could be carried out jointly with research groups in Japan.

The proposal to build closer links between the two countries in the life sciences is one of several recommendations in a report published last week by the OST's newly-formed UK/Japan and Asia-Pacific Advisory Group.

Announcing his support for many of the group's conclusions, David Hunt, the minister for science, said that while existing links had brought substantial benefits to both countries, further attention now needed to be paid to "ensuring that collaborative efforts are in priority areas."

Hunt said that it would be to the advantage of both countries if the areas for collaboration were deliberately targeted. "In this way we can ensure that resources are directed as positively as possible."

Sir William Stewart, the government's chief scientific adviser, said that this approach is similar to that taken by the government last year in giving a focus on wealth creation to the research councils, in particular the new Biotechnology and Biological Sciences Research Council (BBSRC). "This is a continuation into the international arena of what we have done with the BBSRC," says Stewart.

At the same time Denis Noble, professor of physiology at the University of Oxford, and a member of the advisory panel which draw up the report, pointed out that there was a need to maintain links with Japan "outside the targeted areas".

The task of helping to identify areas for potential collaboration has been passed to Sir John Cadogan, the director-general of the research councils, although the group recommends that the final selection of key areas be left to the research councils.

Other recommendations included in the report are that existing schemes to support the exchanges of scientists and technologists should be extended to cover a wider range of disciplines, including engineering; and that a group of British and Japanese patent experts carry out a joint study of patent policies in the two countries, exploring ways in which the two systems might be brought closer in line.

The report also confirmed the British government's view that it would like Japan and the United Kingdom to enjoy "equal status" as members of international efforts such as the European Laboratory for Particle Physics (CERN) and of future neutron and spallation sources. David Dickson
Hikone, Japan. In contrast to the situation in the United States, research in Japanese universities is still isolated from the outside world and does not respond sufficiently to social needs, according to a leading Japanese industrialist.

These views were expressed by Michiyuki Uenohara, executive adviser of NEC Corporation, at a symposium held last week in Hikone, central Japan, and attended by about two dozen university presidents from the two countries and representatives of Japanese industry.

In a panel discussion on interactions with industry, Uenohara said that university researchers in Japan should increase their interaction with the outside world and explore basic research from "the real world".

But Junjiro Kanamori, president of Osaka University, reminded participants that Japan's national universities are formally "branch organizations" of the central government. As a result, he said, the government always "casts a shadow" on relations between universities and industry.

Although links between Japanese universities and industry have grown slightly over the past decade, thanks largely to several new initiatives by the Ministry of Education, Science and Culture, most of the funds for these programmes — $¥ 52$ billion (US\$690 million) out of $¥ 67$ billion in fiscal year 1994 - consist of untied 'donations' from industry. These are primarily used by companies as a tool for recruiting good students and seldom encourage interaction.

According to Uenohara, there are some fundamental flaws in the research environment in Japanese universities that discourage interaction with industry. For example, interdisciplinary research is "rarely" found in the universities. Yet advances in the information technology that Uenohara's company produces depends on research bridging not only natural science and engineering, but also medical and social science.

Kanamori echoed this view, emphasizing that universities must first "get over the sectionalism within themselves" before interactions can flourish. Hiroo Imura, presi-

dent of Kyoto University, also pointed out the lack of mobility among Japanese university researchers compared with those in the United States. Furthermore, he said, Japanese companies "do not employ PhDs", resulting in little cross-fertilization between university and company researchers.

Government regulation also inhibits collaboration. Uenohara pointed out that the present interactions are largely "unidirectional". Industrial researchers can carry out research on campuses, but university researchers are prohibited by law from participating in research projects in industrial laboratories.

Furthermore, they can carry out consultancy work for only one or two hours a week as they are civil servants with government pay cheques. As a result, very few university faculty members understand industrial research or can explain their research in industrial terms.

Several US participants expressed envy of the long-term view of research that Japanese industrial leaders such as Uenohara can take. Japanese industry has in recent years been able to increase its investment in basic research because of the low interest rates in Japan during the bubble economy of the late 1980s. Furthermore, unlike those in the United States, Japanese companies do not have to answer to their stockholders in the short term.

In contrast to the United States, however, government financial regulations severely inhibit venture businesses and entrepreneurship in Japan, according to Naoya Yoda, executive adviser to Toray Corporate Business Research Inc. In particular, restrictions on the flow of funds into venture businesses holds back interaction between universities and industry.

But probably the biggest factor preventing such interaction is university researchers themselves. In reply to a question after the meeting, Kanamori said he does not get the impression that university researchers are pushing for regulations that prevent them from working in company laboratories to be eased.

David Swinbanks

\section{Caskey to head Merck's genome efforts}

Washington. Tom Caskey, the geneticist who has played a leading role in recent moves to establish a map of the human genome available for 'unencumbered' use by researchers in both the private and the public sectors, is to join the US pharmaceutical company Merck as senior vice president for basic research.

Caskey is leaving the department of molecular and human genetics at Baylor College of Medicine in Houston, Texas, to take charge of all Merck's basic research programmes, as well as the human genome sequencing effort that the company is financing at the Washington University in St Louis, Missouri, announced at the end of last month (see Nature 371, 365; $1994)$. 